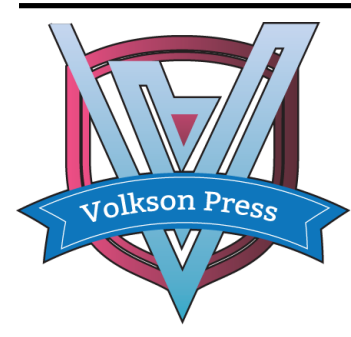

Contents List available at VOLKSON PRESS

New Materials and Intelligent Manufacturing (ICNMIM)

Journal Homepage: https://topicsonchemeng.org.my/

ISBN: 978-1-948012-12-6

\title{
EFFECTS OF THERMAL ETCHING CONDITIONS ON SEM OBSERVATIONS OF TWO KINDS OF $\mathrm{BaTiO}_{3}$-BASED CERAMICS
}

\author{
Yongshun Zheng, Dayong Lu* \\ Key Laboratory for Special Functional Materials in Jilin Provincial Universities, Jilin Institute of Chemical Technology Chengde Street 45, Jilin \\ 132022, China \\ *Corresponding Author Email: dylu@jlict.edu.cn
}

This is an open access article distributed under the Creative Commons Attribution License, which permits unrestricted use, distribution, and reproduction in any medium, provided the original work is properly cited

\section{ARTICLE DETAILS ABSTRACT}

Article History:

Received 26 June 2018

Accepted 2 July 2018

Available online 1 August 2018

\begin{abstract}
The effects of thermal etching temperature $\left(T_{\mathrm{te}}\right)$ and time $\left(t_{\mathrm{te}}\right)$ on scanning electron microscope (SEM) observations were investigated using X-ray diffraction (XRD), SEM, backscattered electron (BSE), and dielectric measurements for $\left(\mathrm{Ba}_{1-x} \mathrm{Mg}_{x}\right) \mathrm{TiO}_{3}(x=0.015)(\mathrm{BMT})$ and BETC (not open) ceramics prepared at the sintering temperatures of $T_{\mathrm{s}}=$ $1200{ }^{\circ} \mathrm{C}$ and $1400{ }^{\circ} \mathrm{C}$, respectively. BMT and BETC exhibit a pseudo-cubic and a tetragonal perovskite structures, respectively. When $T_{\mathrm{te}}>T_{\mathrm{s}}$, the crystalline structure, microstructure and dielectric thermal properties change, and at this time the observed SEM image cannot reflect the real morphology of BMT. The $T_{\text {te }}$ should be equal to or less than $T_{\mathrm{s}}$. An optimum condition for clear SEM observations of BETC was determined to be $T_{\mathrm{te}}=1400{ }^{\circ} \mathrm{C}$ for $T_{\mathrm{te}}=18 \mathrm{~min}$, and at this time, the crystalline structure and dielectric properties of BETC did not change. Under a given thermal etching temperature, the thermal etching time has a great influence on the SEM image quality of sample.
\end{abstract}

\section{KEYWORDS}

$\mathrm{BaTiO}_{3}$ ceramics, scanning electron microscope, microstructure, X-ray diffraction, dielectric properties

\section{INTRODUCTION}

Thermal etching is a processing method of making the surface of the polished sample heat-treated at a given temperature for a certain period of time. Thermal etching can cause peak-valley layered structure on the clean surface with low surface energy, because the surface of the sample can be different everywhere. The peak-valley layered structure can clearly show the size of crystallites and the distribution of crystalline phases, thus reflecting their microstructure [1]. Currently, thermal etching technology is being widely used in the analysis of ceramic microstructures and becomes an effective method of preparing SEM samples [2]. The temperature $\left(T_{\mathrm{te}}\right)$ and holding time $\left(t_{\mathrm{te}}\right)$ used for thermal etching are quite different. For example, Jawhara et al. studied $\mathrm{A}_{5} \mathrm{~B}_{4} \mathrm{O}_{15}(\mathrm{~A}=\mathrm{Ba}, \mathrm{Sr}, \mathrm{Mg}, \mathrm{Ca}$, $\mathrm{Zn} ; \mathrm{B}=\mathrm{Nb}, \mathrm{Ta}$ ) microwave dielectric ceramics, and Zheng et al. studied the TZP multiphase ceramics and $\mathrm{Al}_{2} \mathrm{O}_{3}-\mathrm{SiC}$ nanocomposite ceramics $[3,4]$.

They used the etching temperatures of $20-50^{\circ} \mathrm{C}$ and $50-100^{\circ} \mathrm{C}$ lower than the sintering temperature $\left(T_{\mathrm{s}}\right)$, respectively. After 30 minutes of heat preservation, the good thermal erosion results have been achieved. In addition, the $T_{\mathrm{te}}$ of $\alpha-\mathrm{Zn}_{2} \mathrm{SiO}_{4}$ polycrystalline ceramics studied by Chang et al. was $100^{\circ} \mathrm{C}$ lower than $T_{\mathrm{s}}$; after 0.5 to $12 \mathrm{~h}$ of thermal etching, clear SEM topography photos were also obtained [5]. However, it was found that as the thermal etching time increases, the microstructure gradually refines from the grain boundary to the sub grain boundary. Obviously, the selection of thermal etching conditions correlates to morphological structure, preparation methods and other factors.

In this work, $\left(\mathrm{Ba}_{1-x} \mathrm{Mg}_{x}\right) \mathrm{TiO}_{3}$ (BMT) and BETC (not open) ceramics were prepared at different sintering temperatures. The effects of $T_{\mathrm{te}}$ and $t_{\mathrm{te}}$ on SEM image quality of these two ceramics were investigated. By comparison, explain the effect of conditions on the microstructure of SEM samples. An optimum thermal etching condition was suggested.

\section{EXPERIMENTAL}

The initial re-agent powders $\mathrm{BaCO}_{3}, \mathrm{TiO}_{2}$, and $\mathrm{MgO}$ were weighed and carefully mixed. BMT ceramics were prepared using a cold-pressing ceramic processing technique according to the formula $\left(\mathrm{Ba}_{1-x} \mathrm{Mg}_{x}\right) \mathrm{TiO}_{3}(x$ $=0.015$ ) [6]. The mixture was calcinated in air at $1100{ }^{\circ} \mathrm{C}$ for $5 \mathrm{~h}$ for decarbonation. The mixture with a PVA binder was then uniaxially pressed at $200 \mathrm{MPa}$ for $2 \mathrm{~min}$ into pellets with $12-\mathrm{mm}$ diameter. The pellets were sintered in air at $T_{\mathrm{s}}=1200{ }^{\circ} \mathrm{C}$ for $12 \mathrm{~h}$. The pellets were densified into crack-free ceramics. BETC ceramic (not open) was prepared according to the same route as BMT. The final sintering conditions were chosen as $T_{\mathrm{s}}=$ $1400^{\circ} \mathrm{C}$ for $12 \mathrm{~h}$.

The surfaces of ceramics were polished and then thermally etched at different temperatures $\left(T_{\text {te }}\right)$ to observe the microstructure using an EVOMA 10 scanning electron microscope (SEM) (Zeiss) operated at 15 $\mathrm{keV}$. To observe the secondary phase, SEM investigations in backscattered electron (BSE) mode were performed. Powder X-ray diffraction (XRD) measurements were performed using a Rint 2200 X-ray diffractometer (Rigaku) for monitoring of heat treatment on crystal structure. All XRD data were collected between $20^{\circ} \leq 2 \theta \leq 85^{\circ}$ at room temperature. Crystal structures were calculated by MS Modeling (Accelry) using Reflex Package and $\mathrm{Cu} K \alpha_{1}$ radiation $(\lambda=1.540562 \AA)$. The polished disks with $0.8-\mathrm{mm}$ thickness were electroded with sputtered $\mathrm{Au}$ atoms and silver paste and then heat-treated at $500{ }^{\circ} \mathrm{C}$ for $30 \mathrm{~min}$ for electrical measurements. The dielectric properties of bulk ceramics were investigated at $1 \mathrm{kHz}$ using a Concept 41 Dielectric/Impedance spectrometer (Novocontrol) with an applied voltage of $1 \mathrm{~V}$.

\section{RESULTS AND DISCUSSION}

The powder XRD patterns of BMT and BETC samples investigated are shown in Figure 1. Two insets show Gaussian fitting of the XRD peaks in the vicinity of $45^{\circ}$. BMT sintered at $T_{\mathrm{s}}=1200{ }^{\circ} \mathrm{C}$ had a pseudo-cubic perovskite structure (space group: $P m 3 m$ ). The Miller indexes are given in 
this figure. The broader (200) peak is characteristic of pseudo-cubic phase (Figure 1a inset). BETC sintered at $T_{\mathrm{s}}=1400^{\circ} \mathrm{C}$ had a tetragonal perovskite structure, as marked by a (002)/(200) peak splitting (Figure $1 \mathrm{~b}$ inset).

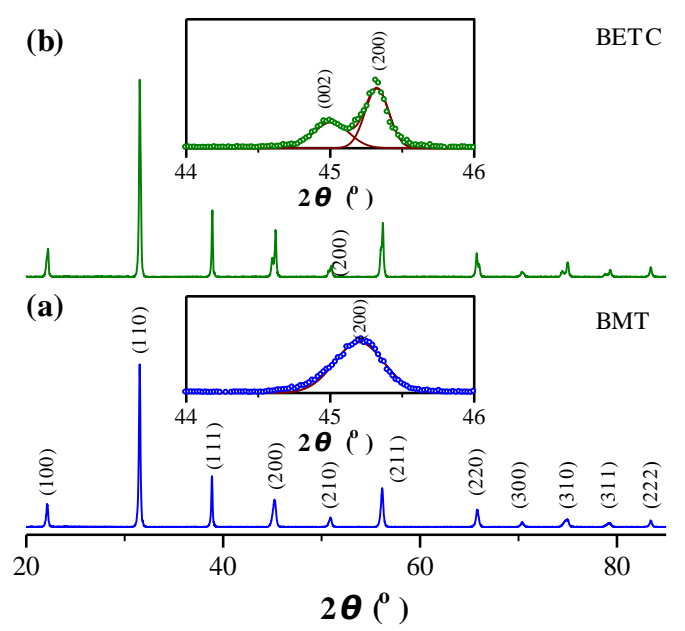

Figure 1: Powder XRD patterns of (a) BMT and (b) BETC ceramics. Two insets show Gaussian fitting of the XRD peaks in the vicinity of $45^{\circ}$.

The SEM images of the surfaces of BMT and the polished and thermally etched surfaces of BMT thermally etched at $T_{\mathrm{te}}=1400{ }^{\circ} \mathrm{C}$ are shown in Figure 2. The average grain size was 0.5 and $0.7 \mu \mathrm{m}$, respectively. Their surface morphologies are clearly visible. Figure $2 \mathrm{a}$ is a micrograph of ceramic surface sintered at $T_{\mathrm{s}}=1200^{\circ} \mathrm{C}$ for $12 \mathrm{~h}$ and shows clear ceramic pores and grains (Figure 2a). After BMT was thermally etched at $T_{\text {te }}=$ $1400{ }^{\circ} \mathrm{C}$ for $t_{\mathrm{te}}=12 \mathrm{~min}$, the porosity decreased, the crystalline grains grew, and the ceramic became denser (Figure $2 \mathrm{~b}$ ). This is because the increase in $T_{\text {te }}$ causes the grain size to become larger [7,8].
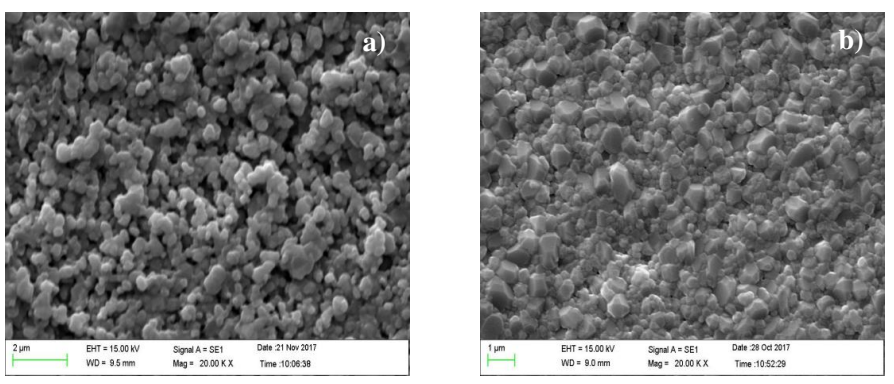

Figure 2: SEM images of (a) the surfaces of BMT ceramic sintered at Ts = $1200^{\circ} \mathrm{C}$ and (b) the polished and thermally etched surfaces of BMT ceramic, Tte $=1400^{\circ} \mathrm{C}$.

In addition, it is possible that the higher thermally etching temperature results in a structural phase transition. For this reason, we prepared BMT ceramic sintered at $T_{\mathrm{s}}=1400{ }^{\circ} \mathrm{C}$. Its XRD pattern is shown in Figure 3. It was found that the crystalline structure of BMT changed from pseudocubic (Figure 1a) to mixed phases of tetragonal (space group: $P 4 \mathrm{~mm}$ ) and hexagonal (space group: $P 63 / \mathrm{mmc}$ ) (Figure 3). Based on the intensity of the main (110) peak at $\sim 31^{\circ}$, it is inferred that the ratios of hexagonal and tetragonal were determined to be $23 \%$ and $77 \%$, respectively. The feature of the mixed phases was further confirmed by BSE, as shown in Figure 4.

The coarse pale grains in white circles belong to the hexagonal phase and they are embedded in a large number of tetragonal grains. The hexagonal phase in BMT originates from both occupations of $\mathrm{Ti}$ sites by $\mathrm{Mg}^{2+}$ and appearance of $\mathrm{O}$ vacancies $\left(\mathrm{V}_{0}\right)$, forming $\mathrm{Mg}^{2+}-\mathrm{V}_{0}$ defect complexes. Kirianov et al. and Dang et al. also reported a similar result about the mixed phases for $\mathrm{Ba}\left(\mathrm{Ti}_{1-x} \mathrm{Mn}_{x}\right) \mathrm{O}_{3}$ with $x<0.03[9,10]$. The Jahn-Teller distortion cased by the Ti-site $\mathrm{Mn}^{3+}$ ions is proposed as the driving force for the phase transition from tetragonal to hexagonal [11]. This implies that $\mathrm{Mg}^{2+}$ and $\mathrm{Mn}^{3+}$ acceptors on the Ti sites in $\mathrm{BaTiO}_{3}$ play a same role in the formation of the hexagonal phase.

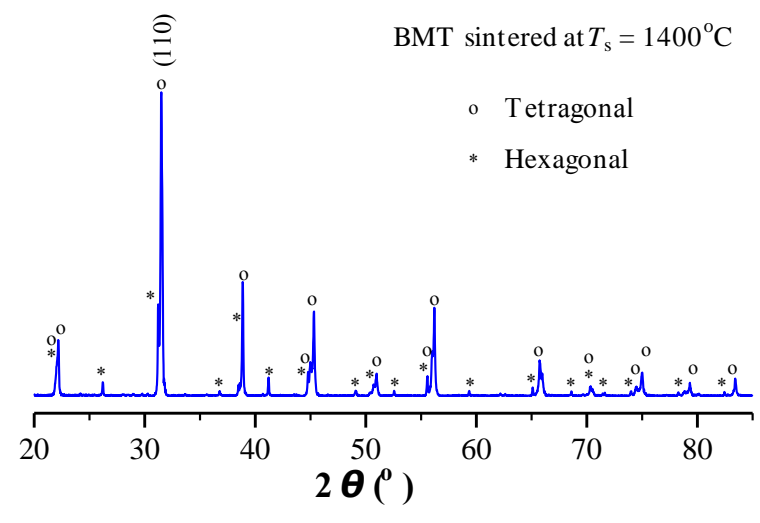

Figure 3: XRD pattern of BMT sintered at Ts $=1400^{\circ} \mathrm{C}$.

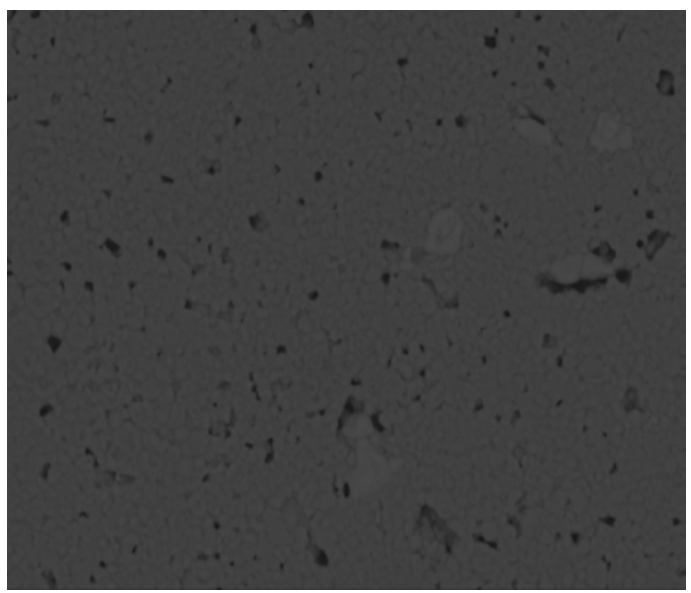

Figure 4: BSE image of BMT sintered at Ts $=1400^{\circ} \mathrm{C}$.

The temperature dependences of the dielectric permittivity $\left(\varepsilon^{\prime}\right)$ for BMT sintered at $T_{\mathrm{s}}=1200$ and $1400{ }^{\circ} \mathrm{C}$ are shown in Figure 5. When $T_{\mathrm{s}}=1200$ ${ }^{\circ} \mathrm{C}$, the $\varepsilon^{\prime}-T$ curve of BMT is smooth and even, with a rounded hill around $T_{\mathrm{m}}=110^{\circ} \mathrm{C}$. The Curie peak of $\mathrm{BaTiO}_{3}$ is dramatically suppressed due to Mg doping and this ceramic satisfies X8S specification with $\varepsilon^{\prime}{ }_{\mathrm{RT}}=1200$. $\mathrm{Mg}^{2+}$ plays an important role as a shell maker in forming a so-called coreshell structure in the $\mathrm{BaTiO}_{3}-\mathrm{MgTiO}_{3}$ system, as suggested by Chang et al. [12]. As $T_{\mathrm{s}}$ is increased to $1400^{\circ} \mathrm{C}$, the bimodal feature in the $\varepsilon^{\prime}-T$ curve is distinct, both $t$ - $c$ and $o-t$ transitions occur at $T_{\mathrm{m}}=106{ }^{\circ} \mathrm{C}$ and $T_{2}=14{ }^{\circ} \mathrm{C}$, respectively.

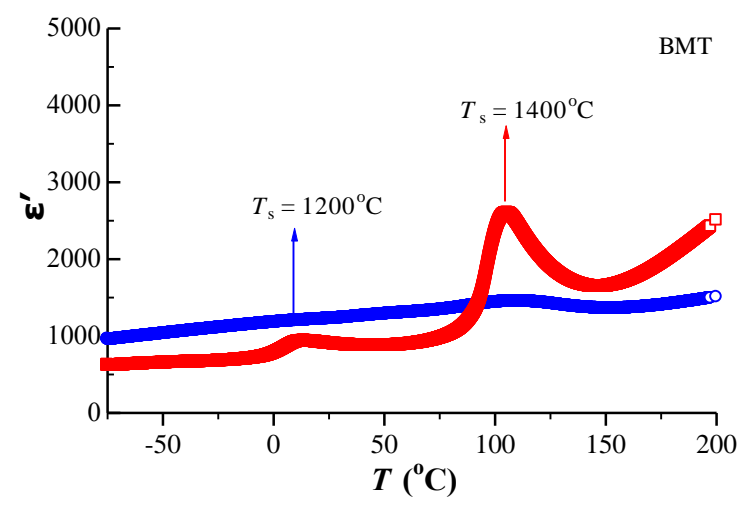

Figure 5: Temperature dependences of $\varepsilon^{\prime}$ for BMT sintered at Ts $=1200$ and $1400{ }^{\circ} \mathrm{C}$.

The above three experiments (Figures 3-5) confirm that $T_{\mathrm{te}}>T_{\mathrm{s}}$ will cause changes in crystalline structure and in dielectric thermal properties, and cannot reflect the real morphology of BMT. At this time, there is no significance in SEM observations under the higher $T_{\text {te. }}$ The thermal etching 
temperature $\left(T_{\mathrm{te}}\right)$ should be equal to or less than the ceramic sintering temperature $\left(T_{\mathrm{s}}\right)$.

A realistic example is that it is difficult to observe a clear micrograph for BETC ceramic sintered at $T_{\mathrm{s}}=1400{ }^{\circ} \mathrm{C}$ when $T_{\mathrm{te}}<T_{\mathrm{s}}$, even if $T_{\mathrm{te}}=T_{\mathrm{s}}$ and $t_{\mathrm{te}}$ $\leq 12 \mathrm{~min}$. For this reason, take $T_{\text {te }}$ as $T_{\mathrm{s}}$. We prolonged thermal etching time $\left(t_{\mathrm{te}}\right)$. The SEM images of polished BETC surfaces, thermally etched at $T_{\mathrm{te}}=$ $1400{ }^{\circ} \mathrm{C}$ for $t_{\mathrm{te}}=12 \mathrm{~min}$ and $18 \mathrm{~min}$ are shown in Figure 6. It can be seen that the morphology in BETC could not be clear observed for $t_{\mathrm{te}}=12 \mathrm{~min}$. As te was prolonged to $18 \mathrm{~min}$, a clear micrograph containing grains and grain boundaries was achieved. Especially, the lamellar domain structures in grains can be clear observed. These experimental results reveal that an optimum thermally etching condition for BETC was determined to be $T_{\mathrm{te}}=$ $1400^{\circ} \mathrm{C}$ for $t_{\mathrm{te}}=18 \mathrm{~min}$. Under the same thermal etching temperature, the thermal etching time has a great influence on the SEM image quality of the sample.
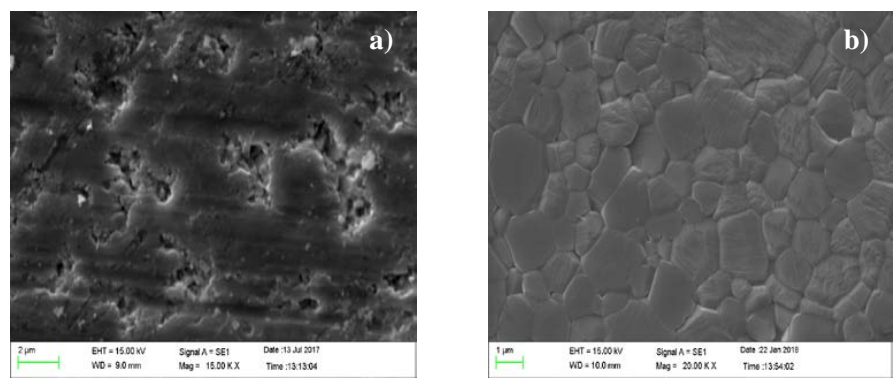

Figure 6: SEM images of polished BETC surfaces, thermally etched at Tte $=1400^{\circ} \mathrm{C}$ for $(\mathrm{a}) \mathrm{t}=12 \mathrm{~min}$ and (b) $18 \mathrm{~min}$.

\section{CONCLUSIONS}

The effects of thermal etching temperature $\left(T_{\mathrm{te}}\right)$ and time $\left(t_{\mathrm{te}}\right)$ on SEM observations were investigated for $\left(\mathrm{Ba}_{1-x} \mathrm{Mg}_{x}\right) \mathrm{TiO}_{3}(x=0.015)$ (BMT) and BETC (not open) ceramics sintered at $T_{\mathrm{s}}=1200{ }^{\circ} \mathrm{C}$ and $1400{ }^{\circ} \mathrm{C}$, respectively. BMT and BETC exhibit a pseudo-cubic and a tetragonal perovskite structures, respectively. When $T_{\mathrm{te}}>T_{\mathrm{s}}$, the crystalline structure of BMT changes from pseudo-cubic to mixed phases of tetragonal and hexagonal, and the microstructure and dielectric thermal properties change. At this time, the observed SEM image cannot reflect the real morphology of BMT. The thermal etching temperature $\left(T_{\text {te }}\right)$ should be equal to or less than the ceramic sintering temperature $\left(T_{\mathrm{s}}\right)$. For BETC ceramic difficult to observe a clear micrograph under the conditions of $T_{\text {te }}$ $<T_{\mathrm{s}}$ or $T_{\mathrm{te}}=T_{\mathrm{s}}$ and $t_{\mathrm{te}} \leq 12 \mathrm{~min}, \mathrm{BETC}$ heat-treated at $T_{\mathrm{s}}=1400{ }^{\circ} \mathrm{C}$ still remained a tetragonal perovskite structure. An optimum thermally etching condition was determined to be $T_{\mathrm{te}}=1400^{\circ} \mathrm{C}$ for $t_{\mathrm{te}}=18 \mathrm{~min}$, which reveals that under the same thermal etching temperature, the thermal etching time has a great influence on the SEM image quality of sample.

\section{ACKNOWLEDGEMENTS}

This work was funded by the projects of the National Natural Science Foundations of China (21271084) and Jilin Province (20160101290JC), and Changbai Mountain Scholar Distinguished Professor (2015047).

\section{REFERENCE}

[1] Zou, H., Hood, G.M., Schultz, R.J., Roy, J.A. 1994. Thermal etching of $\alpha-Z r$ single-crystal surfaces. Applied Surface Science, 90, 59-64.

[2] Tsai, J.F., Belnap, J.D., Shetty, D.K. 1994. Crack Shielding in CeTZP $/ \mathrm{Al}_{2} \mathrm{O}_{3}$ composites: comparison of fatigue and sustained load crack growth specimens. Journal of the American Ceramic Society, 77 (1), 105-117.

[3] Mohanan, T. 2003. $\mathrm{A}_{5} \mathrm{~B}_{4} \mathrm{O}_{15}$ ( $\mathrm{A}=\mathrm{Ba}, \mathrm{Sr}, \mathrm{Mg}, \mathrm{Ca}, \mathrm{Zn} ; \mathrm{B}=\mathrm{Nb}, \mathrm{Ta}$ ) microwave dielectric ceramics. Materials Letters, 57, 4043-4048.

[4] Lang, Y.S., Yang, J.Y., Li, L., Hou, Y.Y. 1997. Application of hot-etch technique in microstructure studies of multiphase ceramics. Journal of Qingdao Institute of Chemical Technology, 18 (1), 31-34.

[5] Chang, C.C., Shen, P. 2000. Thermal-etching development of $\alpha-\mathrm{Zn}_{2} \mathrm{SiO}_{4}$ polycrystals: effects of lattice imperfections, Mn-dopant and capillary force. Materials Science \& Engineering A, 288 (1), 42-46.

[6] Lu, D.Y., Yuan, L.F., Liang, W.N., Zhu, Z.B. 2016. Characterization of oxygen vacancy defects in $\mathrm{Ba}_{1-x} \mathrm{Ca}_{x} \mathrm{TiO}_{3}$ insulating ceramics using electron paramagnetic resonance technique. Japanese Journal of Applied Physics, 55 (1), 011501.

[6] Buscaglia, V., Buscaglia, M.T., Viviani, M., Mitoseriu, L., Nanni, P., Trefiletti, V., Piaggio, P., Gregora, I., Ostapchuk, T., Pokorn'y, J., Petzelt, J. 2006. Grain size and grain boundary-related effects on the properties of nanocrystalline barium titanate ceramics. Journal of the European Ceramic Society, 26 (14), 2889-2898.

[7] Lu, D.Y., Sun, X.Y. Toda, M. 2007. A novel high-k 'Y5V' barium titanate ceramics co-doped with lanthanum and cerium. Journal of Physics and Chemistry of Solids, 68 (4), 650-664.

[8] Kirianov, A., Ozaki, N., Ohsato,H., Kohzu, N., Kishi, H. 2001. Studies on the Solid Solution of $\mathrm{Mn}$ in $\mathrm{BaTiO}_{3}$. Japanese Journal of Applied Physics, 40 (9), 5619-5623.

[9] Dang, N.V., Phan, T.L., Thanh, T.D., Lam, V.D., Hong, L.V. 2012. Structural phase separation and optical and magnetic properties of $\mathrm{BaTi}_{1-\mathrm{x}} \mathrm{Mn}_{\mathrm{x}} \mathrm{O}_{3}$ multiferroics. Journal of Applied Physics, 111 (11), 1804-1814.

[10] Langhammer, H.T., Muller, T., Felgner, K.H., Abicht, H.P. 2000. Crystal structure and related properties of manganese-doped barium titanate ceramics. Journal of the American Ceramic Society, 83 (3), 605-611.

[11] Chang, C.Y., Wang, W.N., Huang, C.Y. 2013. Effect of $\mathrm{MgO}$ and $\mathrm{Y}_{2} \mathrm{O}_{3}$ doping on the formation of core-shell structure in $\mathrm{BaTiO}_{3}$ ceramics. Journal of the American Ceramic Society, 96 (8), 2570-2576. 